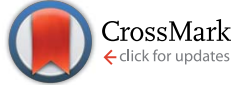

Cite this: RSC Adv., 2017, 7, 71

Received 29th October 2016 Accepted 9th December 2016

DOI: 10.1039/c6ra26016k

www.rsc.org/advances

\title{
Enhanced degradation of gaseous benzene by a Fenton reaction $\uparrow$
}

\author{
Gaoyuan Liu, Haibao Huang, ${ }^{\star}$ Ruijie Xie, Qiuyu Feng, Ruimei Fang, Yajie Shu, \\ Yujie Zhan, Xinguo Ye and Cheng Zhong
}

\begin{abstract}
A wet scrubbing process coupled with advanced oxidation processes (AOP) has raised great interest for the abatement of volatile organic compounds (VOCs) owing to its strong oxidation capacity and few byproducts. Fenton as an AOP has been widely used in wastewater treatment. However, the dosing method of Fenton reagents is not suitable for the treatment of continuous-flow VOCs waste-gas since $\mathrm{H}_{2} \mathrm{O}_{2}$, a major reagent in the Fenton reaction, will be rapidly eliminated. In this study, the Fenton process was used to enhance benzene degradation in an aeration container with intermittent dosing of $\mathrm{H}_{2} \mathrm{O}_{2}$. With the same total dosage of $\mathrm{H}_{2} \mathrm{O}_{2}$, the benzene removal efficiency reached $85 \%$ by intermittent dosing while it was quickly decreased to $0 \%$ by dosing in a lump. The generated $\mathrm{CO}_{2}$ by intermittent dosing of $\mathrm{H}_{2} \mathrm{O}_{2}$ is nearly 3 times that in the latter. In addition, no byproduct was generated in the gas phase. The possible pathways and mechanism of benzene degradation by the Fenton process were proposed according to the detected intermediates in the solution. This study provides a simple and efficient way to significantly enhance VOCs degradation by a Fenton reaction.
\end{abstract}

\section{Introduction}

Many volatile organic compounds (VOCs) are harmful to human health and detrimental to the atmospheric environment. Some of them have potential toxicity and carcinogenicity. ${ }^{1}$ They are key precursors for the formation of atmospheric secondary organic aerosols (SOA) and $\mathrm{O}_{3}$. Many attempts have been made to remove VOCs pollution using physical, chemical and biological methods, ${ }^{2}$ including absorption, ${ }^{3}$ catalytic combustion, ${ }^{4}$ photocatalytic oxidation ${ }^{5}$ and biofilters. ${ }^{6}$ However, these methods still cannot meet with the increasingly stringent discharge standards. For example, the process of adsorption just transfers VOCs from waste gas to the adsorbent but does not destroy them. Catalytic combustion needs expensive catalysts and excessive energy consumption for low-concentration VOCs. Photocatalytic oxidation has some disadvantages such as catalytic deactivation and low efficiency. ${ }^{7}$ Worst of all, these removal methods may produce intermediates, resulting in secondary gaseous pollution. ${ }^{8}$

As an alternative technology, wet scrubbing process coupled with advanced oxidation processes (AOP) has raised great interest in VOCs degradation owing to its merits such as simplicity, strong oxidation capacity and mild reaction

School of Environmental Science and Engineering, Sun Yat-Sen University, Guangzhou, China.E-mail: seabaos@gmail.com

$\dagger$ Electronic supplementary information (ESI) available. See DOI: 10.1039/c6ra26016k conditions., ${ }^{\mathbf{9} 10}$ Fenton reagent, consisting of both $\mathrm{H}_{2} \mathrm{O}_{2}$ and ferrous sulfate, as an AOP has been widely used for wastewater treatment since it can generate highly active, non-specifically but short-lived $\cdot \mathrm{OH} \cdot{ }^{\mathbf{1 1 - 1 4}}$ The overall mechanism of the Fenton reaction is generally known by reaction (1). ${ }^{15,16}$

$$
\mathrm{Fe}^{2+}+\mathrm{H}_{2} \mathrm{O}_{2} \rightarrow \mathrm{Fe}^{3+}+\cdot \mathrm{OH}+\mathrm{OH}^{-}
$$

As for wastewater treatment, the pollutants are generally well mixed with Fenton reagent. Fenton reagents, including $\mathrm{H}_{2} \mathrm{O}_{2}$, could be dosed in a lump, generating $\cdot \mathrm{OH}$ to rapidly degrade contaminants in short time. However, such way of dosing $\mathrm{H}_{2} \mathrm{O}_{2}$ is not suitable for the treatment of waste-gas in continuous-flow since the oxidizing capacity was quickly decreased with the consumption of $\mathrm{H}_{2} \mathrm{O}_{2}$. Recently, photo-Fenton has been used to enhance VOCs degradation ${ }^{2,17}$ while it requires additional UV energy and still become inefficient with the consumption of $\mathrm{H}_{2} \mathrm{O}_{2}$. Therefore, it is of great interest to take simple and efficient steps to enhance oxidation capacity of Fenton reaction for VOCs degradation. In addition, as an emerging method for VOCs degradation, the mechanism of Fenton reaction is still not clear.

In this study, we firstly report the enhanced degradation of VOCs via the Fenton process by intermittent dosing of $\mathrm{H}_{2} \mathrm{O}_{2}$. Toxic and refractory benzene was chosen as a representative VOC. The intermediates from benzene degradation were detected and the possible pathways and mechanism of Fenton process were proposed. 


\section{Experimental methods}

\section{Chemicals and reagents}

In the present study the $\mathrm{H}_{2} \mathrm{O}_{2}(30 \%$ solution, reagent grade) was obtained from Yong Da Chemical Reagents (Tianjin) while ferrous sulfate was provided from Sinopharm Chemical Reagent. Benzene vapor, generated from passing an air stream into a benzene solution, was used as an indicative VOC. The benzene solution was saved in the refrigerator for a stable supply of VOC. The intermediates, generated from the benzene degradation, were extracted by dichloromethane. Both the liquid benzene (analytical grade) and dichloromethane (chromatographic grade) were obtained from Tianjin Fuyu Fine Chemical. Sulfuric acid, which was used to adjust the $\mathrm{pH}$ value of Fenton reagent, was acquired from Guangzhou Chemical Reagent Factory. All the reagents were used without any further purification.

\section{Experimental setup}

Schematic of the experimental setup is shown in Fig. 1. A continuous-flow aeration container, made of Pyrex glass with a diameter of $65 \mathrm{~mm}$, height of $290 \mathrm{~mm}$ and effective volume of $0.5 \mathrm{~L}$, was adopted for generating a stream of air containing the target pollutant. The temperature of the solution in the aeration container was kept at $25{ }^{\circ} \mathrm{C}$ by heat collection-constant temperature type magnetic stirrer (DF-101S, Gongyi Yu Hua Instrument). Air, free of $\mathrm{CO}_{2}$, was generated from a zero air generator (HGA-5L, Beijing Huilong). The air was used to bubble through a benzene solution to generate an air stream containing high concentration of benzene vapor. The benzene vapor was diluted in the buffer and then fed to the bottom of the reactor through an aerator. Flow rate of the simulated gas was set at $1 \mathrm{~L} \mathrm{~min} \operatorname{mon}^{-1}$ and the initial concentration $\left(C_{0}\right)$ of benzene was fixed at $25 \mathrm{ppm}$. Fenton reagents, with $4 \mathrm{mmol}$ of $\mathrm{H}_{2} \mathrm{O}_{2}$ and $1 \mathrm{mmol}$ of ferrous ion, were added into the aeration container. The initial $\mathrm{pH}$ value of the solution was adjusted to 3.0 which is the optimal value for Fenton reactions. ${ }^{18}$ The concentrations of benzene $\left(C_{\mathrm{t}}\right)$, and $\mathrm{CO}_{2}$ (generated from benzene oxidation) in gas phase were measured by a gas chromatograph (GC) (9790II, Fuli) equipped with two flame-ionization detectors (FID). One FID was connected with a Rt-Q-BOND PLOT column $(30 \mathrm{~m} \times$ $0.25 \mathrm{~mm}$ id, film thickness $10 \mu \mathrm{m}$ ) and used for benzene analysis. The other FID equipped with a packed column (TDX-01, $3 \mathrm{~m} \times 3 \mathrm{~mm}$ ) followed by a methanizer which was used to determine the concentrations of $\mathrm{CO}_{2}$. Gas samples from the reaction system were dried and fed to the GC on-line by an

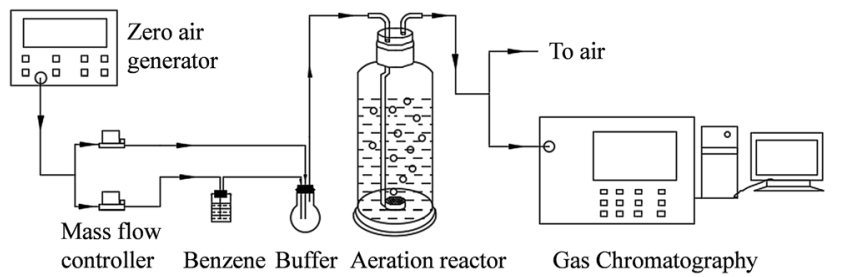

Fig. 1 Schematic of experimental setup. automatic gas sampling valve. The intermediates from benzene degradation in the liquid and gas phase were extracted with dichloromethane and then analyzed by GC-MS (DSQII, Thermo Fisher). The acid substances, which cannot be extracted with dichloromethane from the liquid phase, were detected by the ion chromatography (DX-600, Dionex). The concentrations of $\mathrm{H}_{2} \mathrm{O}_{2},{ }^{19}$ ferrous ion and total $\mathrm{Fe}$ ion in the solution were detected by a spectrophotometer (UV2550, Shimadzu). The concentrations of total carbon (TC), total organic carbon (TOC) and inorganic carbon (IC) were analyzed by a TOC meter (TOC-V $\mathrm{CSH}$, Shimadzu).

\section{Results and discussion}

\section{Benzene degradation by Fenton}

The performance of Fenton reaction for benzene degradation was compared with that of a reference solution made up with pure water. As shown in Fig. 2, without Fenton reagent, benzene removal in the initial stage is mainly ascribed to physical absorption by the water and no $\mathrm{CO}_{2}$ product was observed. In case of pure water, $\mathrm{H}_{2} \mathrm{O}_{2}$ and $\mathrm{Fe}^{2+}$ alone, benzene concentration at the outlet was quickly increased to about $22 \mathrm{ppm}$ in $30 \mathrm{~min}$ due to the saturation of benzene absorption in the aqueous solution. As for Fenton reagent, benzene concentration sharply dropped to below $2.3 \mathrm{ppm}$ and remained at about $5 \mathrm{ppm}$ for $60 \mathrm{~min}$, indicating that benzene was removed continuously by the Fenton reaction. The optimum $\left[\mathrm{H}_{2} \mathrm{O}_{2}\right] /\left[\mathrm{Fe}^{2+}\right]$ ratio for Fenton reaction is approximately $4: 1$ (shown in Fig. $\mathrm{S} 1 \dagger$ ). $\cdot \mathrm{OH}$ generated by the Fenton reagents rapidly attacked the organic molecules. However, with the consumption of the Fenton reagents and the amount of $\cdot \mathrm{OH}$ reduced, leading to a decrease in benzene removal efficiency after 90 min's reaction (shown in Fig. 3). Therefore, it is highly necessary to enhance the oxidizing capacity of the Fenton reaction.

\section{Effect of intermittent dosing of $\mathrm{H}_{2} \mathrm{O}_{2}$}

In the test of intermittent dosing, $4 \mathrm{mmol}_{2} \mathrm{O}_{2}$ was dosed into the $0.5 \mathrm{~L}$ aeration container every $2 \mathrm{~h}$ for 4 rounds while $16 \mathrm{mmol} \mathrm{H}_{2} \mathrm{O}_{2}$ was dosed once at a time as for the test of $\mathrm{H}_{2} \mathrm{O}_{2}$

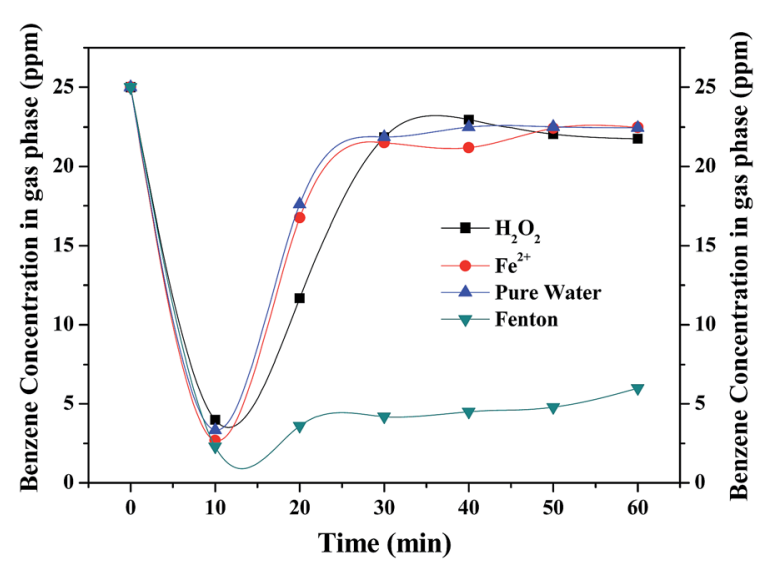

Fig. 2 Comparison of Fenton reaction and reference solution for benzene degradation. 
dosing in a lump. Their performance for benzene degradation is shown in Fig. 3. Benzene removal efficiency $\left[=\left(C_{0}-C_{\mathrm{t}}\right) / C_{0} \times\right.$ $100 \%]$ in gas phase was gradually declined with the consumption of $\mathrm{H}_{2} \mathrm{O}_{2}$ in both cases. Benzene removal efficiency was kept at about $80 \%$ for nearly $90 \mathrm{~min}$ in the test of $\mathrm{H}_{2} \mathrm{O}_{2}$ dosing in a lump. Then, it dropped to near $0 \%$ after 150 min's reaction owing to the depletion of $\mathrm{H}_{2} \mathrm{O}_{2}$ as shown in Fig. 4. In the test of intermittent dosing of $\mathrm{H}_{2} \mathrm{O}_{2}$, the oxidizing capacity was kept for much longer time. The profiles of benzene degradation are similar in the 4 rounds of $\mathrm{H}_{2} \mathrm{O}_{2}$ dosing with benzene removal efficiency reached $85 \%$ in each run. After the benzene removal efficiency dropped to near $0 \%$, the oxidizing capacity of Fenton was quickly recovered with the addition of $\mathrm{H}_{2} \mathrm{O}_{2}$. It is clear that benzene degradation via Fenton was greatly enhanced by intermittent dosing of $\mathrm{H}_{2} \mathrm{O}_{2}$. As for $\mathrm{H}_{2} \mathrm{O}_{2}$ dosing in a lump, $\mathrm{H}_{2} \mathrm{O}_{2}$ was soon consumed and abundant $\cdot \mathrm{OH}$ were generated while only part of the $\cdot \mathrm{OH}$ was used for benzene degradation due to its short-lived life. However, $\cdot \mathrm{OH}$ can be continuously generated and used for the degradation of continuous-flow benzene waste gas in the case of intermittent dosing of $\mathrm{H}_{2} \mathrm{O}_{2}$. It is expected that continuous supply of $\mathrm{H}_{2} \mathrm{O}_{2}$ or shorter interval

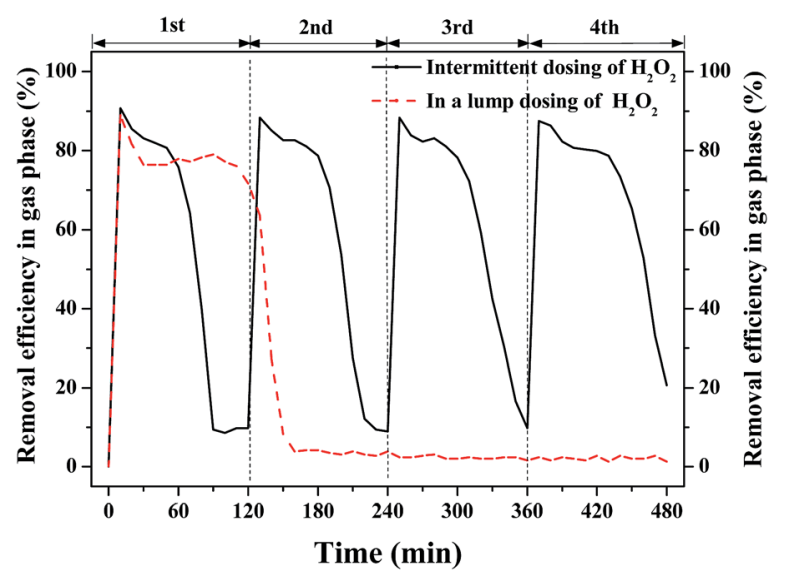

Fig. 3 Profiles of intermittent and lump dosing of $\mathrm{H}_{2} \mathrm{O}_{2}$ for benzene degradation.

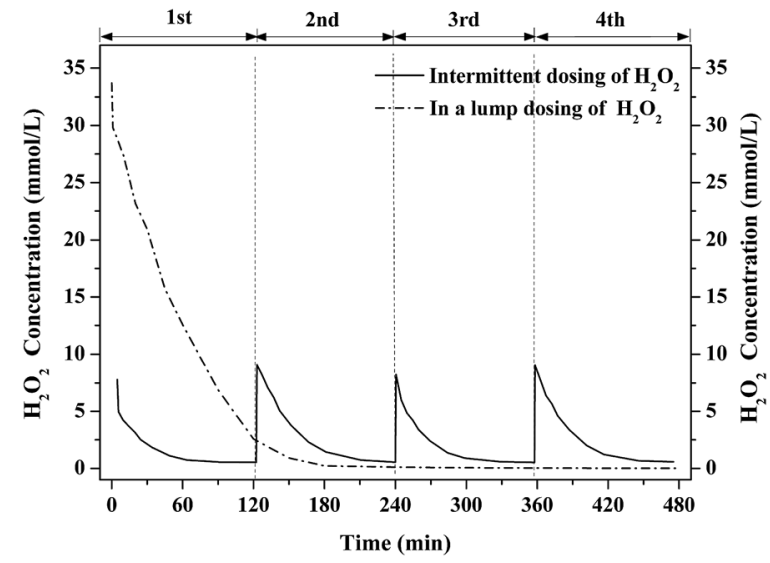

Fig. 4 The concentration change of $\mathrm{H}_{2} \mathrm{O}_{2}$ with intermittent and lump dosing. time of $\mathrm{H}_{2} \mathrm{O}_{2}$ dosing would further improve the oxidizing ability.

Fig. 5 shows the concentration of $\mathrm{CO}_{2}$ generated from benzene degradation by Fenton with the intermittent and the lump dosing cases. $\mathrm{CO}_{2}$ was quickly generated due to the generation of $\cdot \mathrm{OH}$ through the addition of $\mathrm{H}_{2} \mathrm{O}_{2}$ but its concentration dropped as the $\mathrm{H}_{2} \mathrm{O}_{2}$ was gradually consumed. The $\mathrm{CO}_{2}$ concentration reached $45 \mathrm{ppm}$ after 30 min's reaction in the case of $\mathrm{H}_{2} \mathrm{O}_{2}$ dosing in a lump and dropped to nearly $0 \mathrm{ppm}$ after 150 min's reaction. This is not completely consistent with the result of benzene removal efficiency probably due to the absorption of benzene and $\mathrm{CO}_{2}$ in the solution. As for intermittent dosing of $\mathrm{H}_{2} \mathrm{O}_{2}$, the $\mathrm{CO}_{2}$ concentration also reached about $45 \mathrm{ppm}$ for the first round while it gradually increased to about $70 \mathrm{ppm}$ in the fourth round. $\cdot \mathrm{OH}$ can be continuously generated in the case of intermittent dosing of $\mathrm{H}_{2} \mathrm{O}_{2}$. $\mathrm{CO}_{2}$ was formed not only from benzene degradation but also from the degradation of the intermediates in the solution. For the whole process, the $\mathrm{CO}_{2}$ yield with intermittent dosing of $\mathrm{H}_{2} \mathrm{O}_{2}$ is nearly 3 times of that of $\mathrm{H}_{2} \mathrm{O}_{2}$ dosing in a lump. It confirms that intermittent dosing of $\mathrm{H}_{2} \mathrm{O}_{2}$ can greatly enhance VOCs and its intermediates.

Theoretically, nearly $150 \mathrm{ppm}$ of $\mathrm{CO}_{2}$ can be produced if all the removed benzene was completely oxidized into $\mathrm{CO}_{2}$. However, the measured concentration of $\mathrm{CO}_{2}$ at outlet is much lower than the theoretical value. $\sim 25 \%$ of $\mathrm{CO}_{2}$ (shown in Fig. S2 $\dagger$ ) was dissolved in solution, which was confirmed by IC. The residual removal benzene was oxidized into intermediates in gas-phase or liquid phase. However, no gaseous intermediates were detected by the GC-MS, showing that no by-product was discharged in the effluent during benzene degradation by Fenton reaction. The aqueous products of benzene degradation by intermittent dosing of $\mathrm{H}_{2} \mathrm{O}_{2}$ were analyzed by a TOC analyzer. The concentrations of TC, TOC and IC in the solution are shown in Fig. 6. Both TOC and IC were detected, and the TOC concentration was much larger than the IC concentration. IC mainly comes from mineralized products from benzene degradation and TOC mainly comes from intermediates or benzene dissolved in the solution. Both the IC and TOC concentration

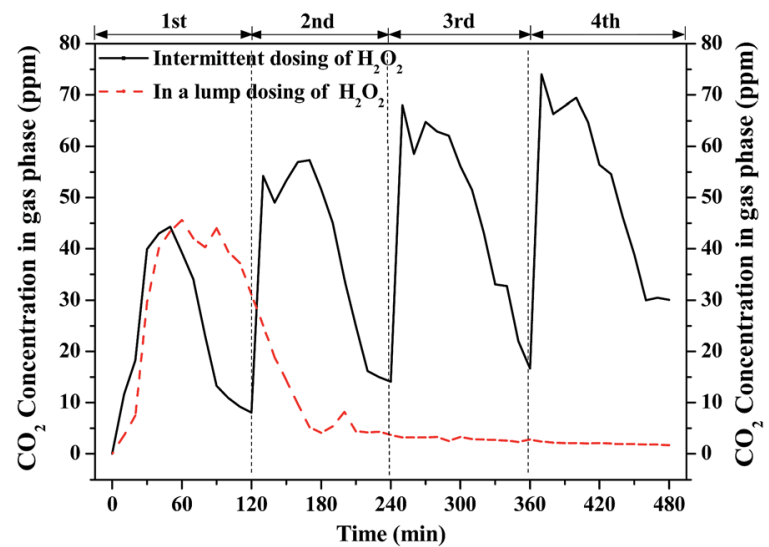

Fig. 5 Profiles of $\mathrm{CO}_{2}$ concentration with intermittent and lump dosing of $\mathrm{H}_{2} \mathrm{O}_{2}$. 


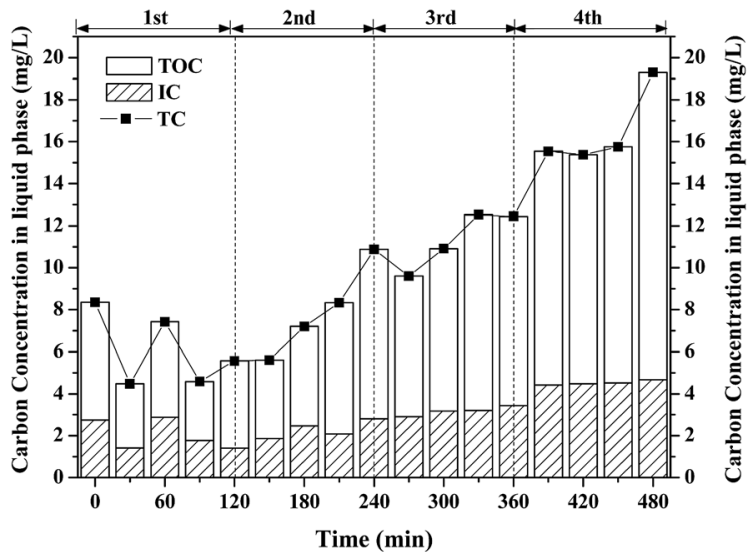

Fig. 6 Profiles of carbon in liquid with intermittent dosing of $\mathrm{H}_{2} \mathrm{O}_{2}$.

increased, from $1.5 \mathrm{mg} \mathrm{L}^{-1}$ to $4.6 \mathrm{mg} \mathrm{L}^{-1}$ and from $2.6 \mathrm{mg} \mathrm{L}^{-1}$ to $14.8 \mathrm{mg} \mathrm{L}^{-1}$, respectively. This indicated that the intermediates formed are soluble and could be easily trapped in the solution. The TOC concentration decreased after each dosing of $\mathrm{H}_{2} \mathrm{O}_{2}$, indicating that part of the intermediates were further oxidized by the Fenton reaction. This agrees well with the observed results of $\mathrm{CO}_{2}$ concentration variation profile shown in Fig. 5 .

\section{Mechanism of benzene degradation}

Benzene degradation by Fenton reaction in an aeration container involves gas-liquid mass transfer of gaseous benzene and the following oxidation of dissolved benzene in the liquid, as shown in Fig. 7. Gaseous benzene was transferred into the liquid phase through the bubbling and the transfer rate of absorption is proportional to the driving force. ${ }^{16}$ As shown in Fig. 2, water has poor capacity for benzene absorption. However, the quick degradation of dissolved benzene in the solution can promote continuous benzene absorption.

Fenton reaction involves electron transfer, leading to the generation of $\cdot \mathrm{OH}$ with strong oxidation capacity. The generation of $\cdot \mathrm{OH}$ is characterized by the reaction (1).

$\mathrm{Fe}^{2+}$ initiates the decomposition of $\mathrm{H}_{2} \mathrm{O}_{2}$ to generate $\cdot \mathrm{OH}$. Fig. 8 shows the profiles of the concentration of $\mathrm{Fe}$ ions in the solution with intermittent dosing of $\mathrm{H}_{2} \mathrm{O}_{2}$. In the first round, the concentration of $\mathrm{Fe}^{2+}$ rapidly dropped from $101.0 \mathrm{mg} \mathrm{L}^{-1}$ to $2.1 \mathrm{mg} \mathrm{L} \mathrm{L}^{-1}$ as $\mathrm{H}_{2} \mathrm{O}_{2}$ was added into the solution and slightly increased to $7 \mathrm{mg} \mathrm{L}^{-1}$, indicating that partial $\mathrm{Fe}^{3+}$ can also be recovered to $\mathrm{Fe}^{2+}$, according to Fenton-like reactions (2) and (3)..$^{20,21}$
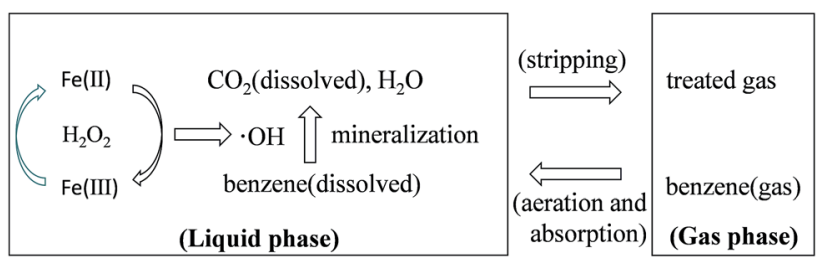

Fig. 7 Schematic of benzene degradation by Fenton reaction in an aeration container.

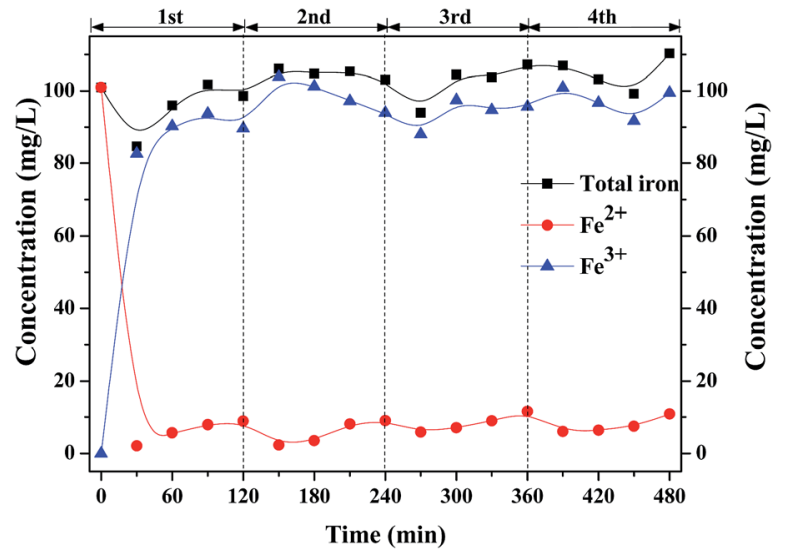

Fig. 8 Profiles of the concentration of $\mathrm{Fe}$ ions in liquid with intermittent dosing of $\mathrm{H}_{2} \mathrm{O}_{2}$.

$$
\begin{gathered}
\mathrm{Fe}^{3+}+\mathrm{H}_{2} \mathrm{O}_{2} \rightarrow \mathrm{Fe}^{2+}+\mathrm{HO}_{2} \cdot+\mathrm{H}_{2} \mathrm{O} \\
\mathrm{Fe}^{3+}+\mathrm{HO}_{2} \cdot \rightarrow \mathrm{Fe}^{2+}+\mathrm{O}_{2}+\mathrm{H}^{+}
\end{gathered}
$$

As shown in Fig. 8, most of them were converted into $\mathrm{Fe}^{3+}$ which seems difficult to be reduced back to $\mathrm{Fe}^{2+}$ through $\mathrm{H}_{2} \mathrm{O}_{2}$, whose reaction rate constant is only $0.02 \mathrm{M}^{-1} \mathrm{~s}^{-1} \cdot{ }^{22-24}$ Future work should be focused on the efficient transfer path of $\mathrm{Fe}^{3+}$ back to $\mathrm{Fe}^{2+}$.

The gaseous and aqueous intermediates from benzene degradation were identified by the GC-MS and the ionchromatograph. No intermediates from benzene degradation were detected in the gas phase, which can prevent the discharge of gaseous by-products. ${ }^{17}$ As listed in Table 1 , the intermediates

Table 1 Intermediates of benzene degradation by Fenton process in

\begin{tabular}{|c|c|c|}
\hline No. & Intermediates & Structure \\
\hline & & $\mathrm{OH}$ \\
\hline 1 & Phenol & \\
\hline 2 & Pyrocatechol & \\
\hline 3 & $P$-Benzoquinone & \\
\hline 4 & Formic acid & \\
\hline 5 & Acetic acid & \\
\hline 6 & Oxalic acid & \\
\hline
\end{tabular}
the liquid phase 


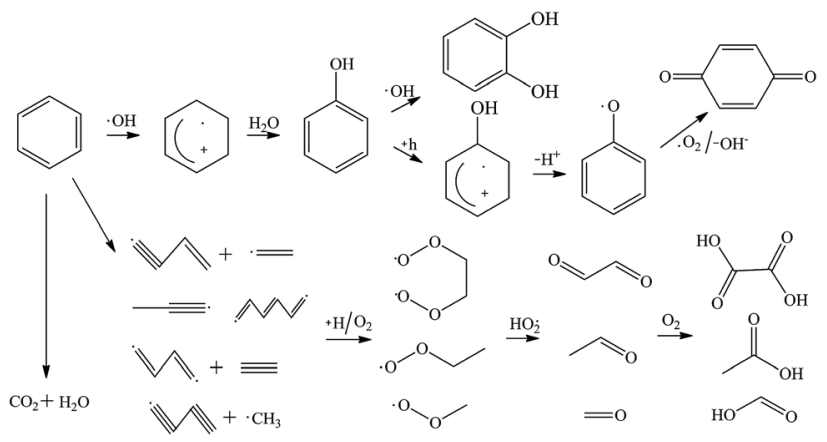

Fig. 9 Mechanism and pathways of benzene degradation by Fenton process.

in the solution are mainly phenolic, $p$-benzoquinone and acid substances dissolved. Phenol, observed by the GC-MS at $\mathrm{m} / z$ 94, is the main by-product in liquid for the Fenton process. The intensity of phenol peaks was gradually increased with intermittent dosing of $\mathrm{H}_{2} \mathrm{O}_{2}$ (shown in Fig. $\mathrm{S} 3 \dagger$ ), which accounts for the increased TOC concentration (Fig. 6). The residual phenol in solution can be easily removed by dosing more Fenton regent ${ }^{25-27}$ or treated in a separate sewage treatment process. Thus, Fenton also can be used as pretreatment method for the degradation of low-concentration VOCs.

Based on the intermediates above, the possible pathways of benzene degradation were composed of benzene ring excitation and pyrolysis. $\cdot \mathrm{OH}$ is highly active and rapidly attack benzene and its degradation intermediates, generating $\mathrm{CO}_{2}$ and $\mathrm{H}_{2} \mathrm{O}^{28-30}$ It was reported that benzene could be dehydrogenated and cleaved by $\cdot \mathrm{OH}$, forming unsaturated hydrocarbon and radicals. ${ }^{31}$ The unsaturated hydrocarbon can react with active hydrogen and oxygen, generating aldehydes. ${ }^{32}$ The aldehydes were further oxidized into acid substances such as formic acid, acetic acid and oxalic acid. ${ }^{33}$ The excited benzene ring is firstly oxidized by $\cdot \mathrm{OH}$ to form phenol, which is further oxidized into pyrocatechol and $p$-benzoquinone. ${ }^{34,35}$ According to the detected products and by-products, the probable pathways of benzene degradation by the Fenton process were proposed as shown in Fig. 9.

\section{Conclusions}

In this study Fenton reaction was used for VOCs degradation in an aeration container. Benzene degradation was greatly enhanced by intermittent dosing of $\mathrm{H}_{2} \mathrm{O}_{2}$. With the same total dosage of $\mathrm{H}_{2} \mathrm{O}_{2}$, benzene removal efficiency reached $85 \%$ and the oxidation capacity was kept for longer time with intermittent dosing of $\mathrm{H}_{2} \mathrm{O}_{2}$ while the removal efficiency quickly decreased to $0 \%$ for the case of $\mathrm{H}_{2} \mathrm{O}_{2}$ dosing in a lump. The generated $\mathrm{CO}_{2}$ by intermittent dosing of $\mathrm{H}_{2} \mathrm{O}_{2}$ is nearly 3 times of that in the latter. In addition, no gaseous intermediates was generated and discharged. The intermittent dosing of $\mathrm{H}_{2} \mathrm{O}_{2}$ is demonstrated to be suitable for the degradation of continuous-flow waste-gas containing VOCs. The possible pathways and mechanism of benzene degradation by Fenton process were proposed according to the detected intermediates in the liquid phase. This study demonstrates that Fenton reaction is a promising process for the degradation of low-concentration VOCs with few gaseous byproducts under mild reaction conditions.

\section{Acknowledgements}

The authors gratefully acknowledge the financial supports from National Key Research and Development Program (No. 2016YFC0204800), NSFC-RGC (No. 51561165015, No. N_HKU718/15), Guangdong Applied Science and Technology Research \& Development Fund (2015B020236004), Guangdong Special Fund for Science and Technology Development (Hong Kong Technology Cooperation Funding Scheme) (No. 2016A050503022), Science and Technology Project in Guangzhou (No. 2014Y2-00094\&2060404), and the Key Fundamental Research Fund for the Central Universities (15lgjc07).

\section{References}

1 A. Bouzaza, C. Vallet and A. Laplanche, J. Photochem. Photobiol., A, 2006, 177, 212-217.

2 M. Handa, Y. Lee, M. Shibusawa, M. Tokumura and Y. Kawase, J. Chem. Technol. Biotechnol., 2013, 88, 88-97.

3 T. K. Poddar and K. K. Sirkar, J. Membr. Sci., 1997, 132, 229233.

4 W. B. Li, J. X. Wang and H. Gong, Catal. Today, 2009, 148, 8187.

5 F. Dong, Y. Sun, M. Fu, W.-K. Ho, S. C. Lee and Z. Wu, Langmuir, 2011, 28, 766-773.

6 S. Mudliar, B. Giri, K. Padoley, D. Satpute, R. Dixit, P. Bhatt, R. Pandey, A. Juwarkar and A. Vaidya, J. Environ. Manage., 2010, 91, 1039-1054.

7 H. Huang and W. Li, Appl. Catal., B, 2011, 102, 449-453.

8 L. Rizzo, Water Res., 2011, 45, 4311-4340.

9 A. Chebbi, H. Jaoua, S. Loukil, N. Mhiri, N. Ammar, S. Sayadi and M. Chamkha, Int. J. Environ. Sci. Technol., 2016, 13, 571580.

10 A. J. Feitz, J. Guan, G. Chattopadhyay and T. D. Waite, Chemosphere, 2002, 48, 401-406.

11 S. Giannakis, M. I. P. López, D. Spuhler, J. A. S. Pérez, P. F. Ibáñez and C. Pulgarin, Appl. Catal., B, 2016, 198, 431-446.

12 Y. Yuan, B. Lai, P. Yang and Y. Zhou, J. Taiwan Inst. Chem. Eng., 2016, 65, 286-294.

13 L. A. G. Mora-Tovar, F. J. R. Valadez, O. Garcia, D. Fernandez and A. I. Zarate, The Electrochemical Society, 2016, 21, 1139.

14 A. J. dos Santos, M. D. de Lima, D. R. da Silva, S. GarciaSegura and C. A. Martínez-Huitle, Electrochim. Acta, 2016, 208, 156-163.

15 J. Yoon, Y. Lee and S. Kim, Water Sci. Technol., 2001, 44, 1521.

16 R.-S. Juang, S.-H. Lin and M.-C. Yang, J. Membr. Sci., 2005, 255, 79-87.

17 M. Tokumura, Y. Wada, Y. Usami, T. Yamaki, A. Mizukoshi, M. Noguchi and Y. Yanagisawa, Chemosphere, 2012, 89, 1238-1242. 
18 M. Tokumura, M. Baba and Y. Kawase, Chem. Eng. Sci., 2007, 62, 7305-7311.

19 N. V. Klassen, D. Marchington and H. C. E. McGowan, Anal. Chem., 1994, 66, 2921-2925.

20 C. L. Hsueh, Y. H. Huang, C. C. Wang and C. Y. Chen, Chemosphere, 2005, 58, 1409-1414.

21 J. De Laat, Y. H. Dao, N. Hamdi El Najjar and C. Daou, Water Res., 2011, 45, 5654-5664.

22 E. Neyens and J. Baeyens, J. Hazard. Mater., 2003, 98, 33-50.

23 L. Chen, J. Ma, X. Li, J. Zhang, J. Fang, Y. Guan and P. Xie, Environ. Sci. Technol., 2011, 45, 3925-3930.

24 A. Rastogi, S. R. Al-Abed and D. D. Dionysiou, Water Res., 2009, 43, 684-694.

25 L. G. C. Villegas, N. Mashhadi, M. Chen, D. Mukherjee, K. E. Taylor and N. Biswas, Current Pollution Reports, 2016, 2, 157-167.

26 Y. Yavuz, A. Savas Koparal and Ü. Bakir Ögütveren, Chem. Eng. Technol., 2007, 30, 583-586.
27 R. Maciel, G. Sant'Anna and M. Dezotti, Chemosphere, 2004, 57, 711-719.

28 M.-C. Lu, C.-J. Lin, C.-H. Liao, W.-P. Ting and R.-Y. Huang, Water Sci. Technol., 2001, 44, 327-332.

29 J. Yoon, Y. Lee and S. Kim, Water Sci. Technol., 2000, 44, 1521.

30 D. Wu, M. Liu, D. Dong and X. Zhou, Microchem. J., 2007, 85, 250-256.

31 M. Kang, B.-J. Kim, S. M. Cho, C.-H. Chung, B.-W. Kim, G. Y. Han and K. J. Yoon, J. Mol. Catal. A: Chem., 2002, 180, 125-132.

32 M. R. Hoffmann, S. T. Martin, W. Choi and D. W. Bahnemann, Chem. Rev., 1995, 95, 69-96.

33 Y. Luo and D. F. Ollis, J. Catal., 1996, 163, 1-11.

34 R. M. Alberici and W. F. Jardim, Appl. Catal., B, 1997, 14, 5568.

35 J. Zhao and X. Yang, Building and Environment, 2003, 38, 645654. 